\title{
latrogenic Bilateral Simultaneous Pneumothorax: Call for Vigilance
}

\author{
Sunil Kumar Garg, Pragya Garg, Nidhi Anchan, Ashish Jaiswal \\ Department of Critical Care Medicine, NMC Hospital, Dubai, United Arab Emirates
}

\section{Abstract}

Iatrogenic pneumothorax refers to the pneumothorax generated after diagnostic or therapeutic procedure. We report the case of a 40-year-old male who had bilateral simultaneous iatrogenic pneumothorax with pneumomediastinum leading to cardiac arrest situation, due to wrong placement of nebulization kit in spontaneously breathing intubated patient. We report this case for its rarity, due to the critical importance of this cause as a etiology of bilateral simultaneous iatrogenic pneumothorax leading to cardiac arrest situation, and need to understand the importance of continuous training and stress of emergency environment.

Keywords: Iatrogenic bilateral pneumothorax, pneumomediastinum, simultaneous iatrogenic bilateral pneumothorax

\section{INTRODUCTION}

Bilateral pneumothorax is a disease that may cause serious respiratory distress and can be a life-threatening condition. ${ }^{[1]}$ Pneumothorax can be difficult to recognize in critically ill patients. The diagnosis of pneumothorax can be made by physical examination findings or radiographic studies including chest radiographs, ultrasonography, or computed tomography scanning. ${ }^{[2]}$

Iatrogenic pneumothorax is a patient safety indicator, representing a complication of procedures such as transthoracic needle aspiration, thoracentesis, transbronchial biopsy, pleural biopsy, and positive pressure ventilation. ${ }^{[3]}$ Iatrogenic pneumothorax should be a good quality indicator because it is clearly associated with mortality. ${ }^{[4]}$

\section{Case Report}

A 40-year-old male presented in the early morning to emergency department in unconscious state. He was in obvious respiratory distress and gurgling throat sounds were audible. His vital parameters included heart rate, 130/min regular; blood pressure, 150/90 $\mathrm{mmHg}$; respiratory rate, $44 / \mathrm{min}$; and temperature, $37.3^{\circ} \mathrm{C}$.

Though moving all limbs, he was unresponsive. His oxygen saturation was low on pulse oximetry. He was intubated

\begin{tabular}{|l|l|}
\hline \multicolumn{2}{|c|}{ Access this article online } \\
\hline Quick Response Code: & Website: \\
\hline & www.ijccm.org \\
\hline & \\
\hline
\end{tabular}

to protect the compromised airway. On suctioning, lots of aspirated material were removed from the respiratory tract. He was connected to oxygen through T-connector attached to endotracheal tube. His chest X-ray was showing bilateral opacities, and arterial blood gas analysis was relevant for respiratory alkalosis and hypoxia. Other laboratory parameters were normal except raised white blood cell count. While awaiting admission to Intensive Care Unit (ICU), the physician advised to give salbutamol nebulization in view of bronchospasm. He was given nebulization in an inappropriate manner by staff. The patient's oxygen and T-connector were removed and the nebulization chamber was connected directly to the endotracheal tube, leaving no port for exhalation. Within few seconds of starting nebulization, the patient collapsed. He stopped moving his limbs, without any respiration and pulse disappeared. Unable to understand the situation, the staff immediately informed the doctor and Code Blue was announced. Monitor was showing tachycardia but no pulse. The physician immediately recognized the wrong connection of nebulizer and removed it. The patient was given ventilation through ambu bag connected to endotracheal

Address for correspondence: Dr. Sunil Kumar Garg, Sarvodaya Hospital, Faridabad, Haryana, India. E-mail: sucare12@yahoo.co.in

This is an open access article distributed under the terms of the Creative Commons Attribution-NonCommercial-ShareAlike 3.0 License, which allows others to remix, tweak, and build upon the work non-commercially, as long as the author is credited and the new creations are licensed under the identical terms.

For reprints contact: reprints@medknow.com

How to cite this article: Garg SK, Garg P, Anchan N, Jaiswal A. Iatrogenic bilateral simultaneous pneumothorax: Call for vigilance. Indian J Crit Care Med 2017;21:607-9. 
tube. A strong suspicion of pneumothorax was made based on the event leading to collapse and increased resistance during ventilation. Immediate $\mathrm{X}$-ray was done which revealed the presence of bilateral pneumothorax [Figure 1]. Bilateral intercostal tube drainage was done and the patient was shifted to the ICU for further management. His lungs expanded bilaterally. Later, he developed acute respiratory distress syndrome during ICU stay, most likely as a result of direct lung injury due to aspiration. After 7 days of ICU stay, the patient improved and was weaned off from ventilator. Both implantable cardioverter defibrillators were removed and he was shifted out of ICU on the $10^{\text {th }}$ day. He remained hospitalized for another 6 days in the ward before discharge and revisited hospital 3 days thereafter in stable condition and then lost to follow-up.

\section{Discussion}

In clinical practice, spontaneous pneumothorax is a frequently encountered disease and there is usually an underlying lung disease, such as chronic obstructive pulmonary disease, malignant neoplasm, or lung tuberculosis. ${ }^{[1]}$ However, bilateral pneumothoraces are rare and represent approximately $1 \%$ of all pneumothorax cases, ${ }^{[5]}$ and bilateral simultaneous iatrogenic pneumothorax is extremely rare. Though various case reports are available on bilateral iatrogenic pneumothorax ranging from those which developed during central venous cannulation, tracheostomy, transbronchial lung biopsy, superficial muscular needle electromyography, acupuncture, and reduction mammoplasty to during subdural peritoneal shunting. We did not find any similar case reported so far, could be due to underreporting.

Nebulization is a very frequent therapeutic intervention in hospital settings. While patient is on spontaneous breathing, it is provided with a nebulization mask or metered dose inhaler (MDI) with or without spacer. On ventilator, nebulization kit is connected with ventilatory circuit around $30 \mathrm{~cm}$ from Y-piece on inspiratory limb or it is given through MDI

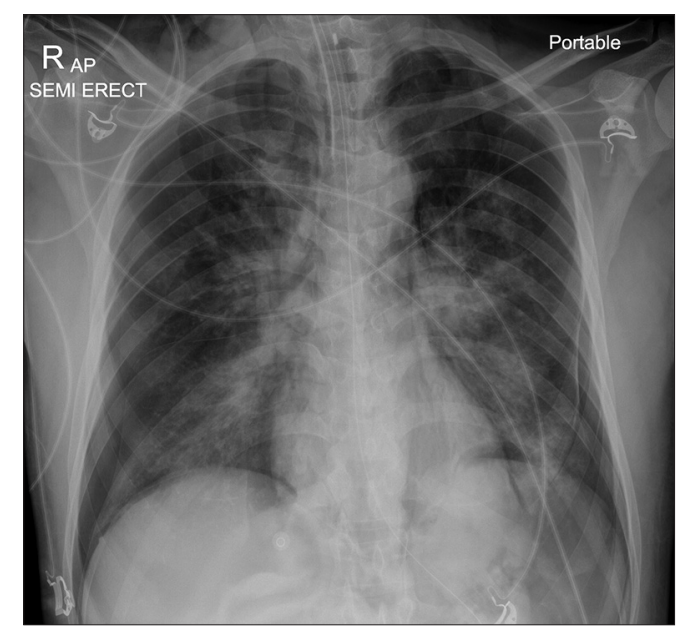

Figure 1: Bilateral pneumothorax with pneumomediastinum connected to spacer in the inspiratory limb of ventilatory circuit. Nebulization is also being provided to patients who are spontaneously breathing while having artificial airway in place by attaching T-piece nebulization chamber to T-connector [Figure 2].

Majority of patients in emergency department who receive nebulization are either spontaneously breathing or breathing through artificial airway with ventilator or bag valve mask attached. To provide nebulization to spontaneously breathing patients with artificial airway in place is rather uncommon occurrence in emergency department settings. In our case, the patient was intubated but was breathing spontaneously and connected to oxygen through T-connector. On physician's request, the staff connected the nebulization chamber directly to the endotracheal tube after removing T-connector, so leaving no port for exhalation. This led to a sudden increase in intrathoracic pressure in a patient who was having bronchospasm leading to bilateral pneumothorax with pneumomediastinum and pulseless electrical activity. On evaluating the incidence completely, it was found that probably less use of this method of nebulization in emergency department coupled with stress of emergency led to this event. The staff was aware of this method of nebulization delivery but did not anticipate the consequences of wrong placement and inappropriately placed the nebulization chamber under the stress of emergency environment.

\section{Conclusion}

We recommend that education and training should be a continuous process, and approach to basics of all interventions should be taught to all caregivers so that they may be in a better position to understand the consequences of any deviation from standard. It is also important to train them in handling stress in emergency situation.

\section{Financial support and sponsorship Nil.}

\section{Conflicts of interest}

There are no conflicts of interest.

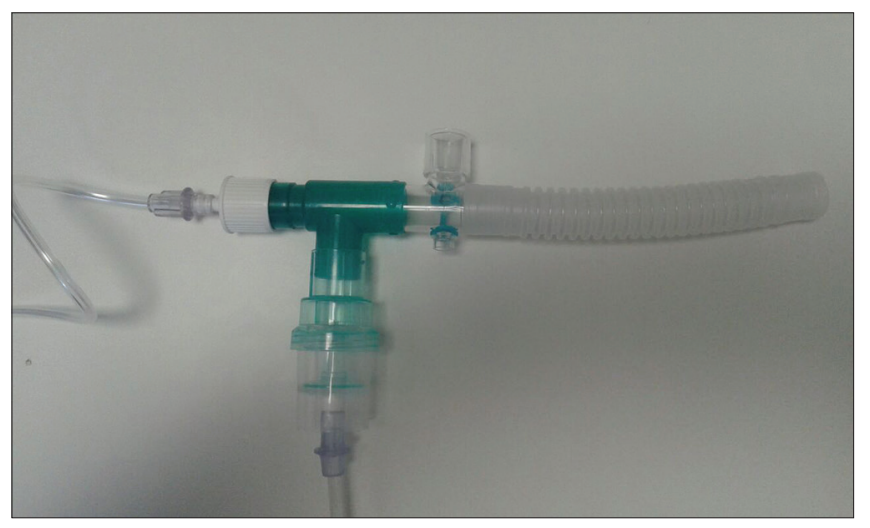

Figure 2: T-connector attached to T-piece nebulization chamber 


\section{RefEREnCes}

1. Aydin Y, Turkyilmaz A, Intepe YS, Eroglu A. Simultaneous bilateral spontaneous pneumothorax: A rare emergency clinical condition. Eurasian J Med 2010;42:5-8.

2. Yarmus L, Feller-Kopman D. Pneumothorax in the critically ill patient. Chest 2012;141:1098-105.

3. John J, Seifi A. Incidence of iatrogenic pneumothorax in the United
States in teaching vs. non-teaching hospitals from 2000 to 2012. J Crit Care 2016;34:66-8.

4. de Lassence A, Timsit JF, Tafflet M, Azoulay E, Jamali S, Vincent F, et al. Pneumothorax in the Intensive Care Unit: Incidence, risk factors, and outcome. Anesthesiology 2006;104:5-13.

5. Morjaria JB, Lakshminarayana UB, Liu-Shiu-Cheong P, Kastelik JA. Pneumothorax: A tale of pain or spontaneity. Ther Adv Chronic Dis 2014;5:269-73. 